\title{
Documentação Audiovisual na Ciência da Informação e Ciências da Comunicação
}

\section{Audiovisual Documentation in Information Science and Communication Sciences}

\author{
José Jullian Souza ${ }^{1}$ \\ ${ }^{1}$ Universidade Federal do Cariri, (UFCA), Juazeiro do Norte, Ceará, Brasil. ORCID: https://orcid.org/0000-0002-4007-8545
}

Autor para correspondência/Mail to: José Jullian Souza, jullianjose64@gmail.com

Recebido/Submitted: 21 de julho de 2020; Aceito/Approved: 05 de outubro de 2020

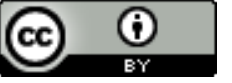

Copyright (c) 2021 Souza. Todo o conteúdo da Revista (incluindo-se instruções, política editorial e modelos) está sob uma licença Creative Commons Atribuição 4.0 Internacional. Ao serem publicados por esta Revista, os artigos são de livre uso em ambientes educacionais, de pesquisa e não comerciais, com atribuição de autoria obrigatória. Mais informações em http://revistas.ufpr.br/atoz/about/submissions\#copyrightNotice.

\begin{abstract}
Resumo
Introdução: Propõe identificar produções científicas brasileiras sobre documentação audiovisual, visualizada como um campo pouco explorado cientificamente, quando comparado a outros campos e abordagens documentais na Ciência da Informação e Ciências da Comunicação. Estas se apresentam como áreas que dialogam acerca do documento audiovisual, assim, a pesquisa estabelece uma visão da temática em paralelo nestas duas áreas do conhecimento tendo como objetivo central identificar as produções existentes acerca da temática da documentação. Quanto aos objetivos basilares: a) coletar a produção científica a partir de: artigo de anais, artigo de periódico, dissertação e tese e b) analisar a datificação e a área de concentração das produções científicas identificadas. Método: Os procedimentos metodológicos são construídos a partir da abordagem quanti-qualitativa, uso da estratégia de pesquisa exploratória-descritiva para a avaliação e aprofundamento diante das informações disponíveis na tentativa de explicar o contexto do fenômeno, tendo como recorte de análise entre 1984 a 2019. Resultados: A produção científica sobre a documentação audiovisual no Brasil, dentro do recorte desta pesquisa, aponta, inicialmente, para uma produção rasa e incipiente, com poucas discussões e um aprofundamento do corpus teórico-pragmático nos últimos anos. Conclusão: A pesquisa contribui para uma visualização dos estudos sobre documentação audiovisual, a partir do caráter quantitativo e qualitativo, demonstrando os percalços e os avanços das abordagens sobre a temática em questão em pesquisas na área da informação e comunicação. Além de apontar a necessidade da construção de espaços científicos para ampliar a discussão e produção sobre os documentos audiovisuais.
\end{abstract}

Palavras-chave: Documentação audiovisual; Ciência da Informação; Ciências da Comunicação.

\begin{abstract}
Introduction: The study proposes to identify Brazilian scientific productions on audiovisual documentation, viewed as a field that is little explored scientifically when compared to other fields and documentary approaches in Information Science and Communication Sciences. These present themselves as areas that dialogue about the audiovisual document. Thus, the research establishes a holistic view of the subject, in parallel in these two areas of knowledge, to identify the existing productions on the field of documentation. As for the basics objectives: a) to collect scientific production from annals article, journal article, dissertation, and thesis and b) to analyze the datafication and the area of concentration of the identified scientific studies Methods: The methodological procedures are built from the quantitative-qualitative approach, using the exploratory-descriptive research strategy for the evaluation and deepening in the face of the available information. It had an attempt to explain the context of the phenomenon, with the analysis cut between 1984 to 2019. Results: The scientific production on audiovisual documentation in Brazil, within the scope of this research, points, initially, to shallow and incipient production, with few discussions and a deepening of the theoretical-pragmatic corpus in recent years. Conclusion: The research contributes to a visualization of the studies on audiovisual documentation, based on the quantitative and qualitative character. It shows the obstacles and advances in the field's approaches in question in research in the area of information and communication. Also, it points out the need to build scientific spaces to expand the discussion and production of audiovisual documents.
\end{abstract}

Keywords: Audiovisual documentation; Information Science; Communication Sciences.

\section{INTRODUÇÃO}

A imagem faz parte da humanidade desde que o homem pré-histórico riscou a parede da caverna e, assim, registrou os primeiros indícios documentais (ainda que não racional e intencionalmente). De lá para cá, a imagem foi sendo transformada e a sua evolução obteve a introdução de novos elementos como o movimento e a sonoridade, originando o desenvolvimento da linguagem audiovisual. Nesta vertente, a transição e o fortalecimento do registro imagético foi construindo "[...] um mundo dominado por imagens e sons obtidos 'diretamente' da realidade, seja pela encenação ficcional, seja pelo registro documental, por meio de aparatos técnicos cada vez mais sofisticados" (Napolitano, 2016, p. 235).

Neste universo da imagem, este estudo centra-se no audiovisual, que de acordo com Cebrián-Herreros (2007, p. 53) é "[...] tudo o que pertence ou é relativo ao uso simultâneo e/ou alternativo do visual e auditivo e, em segundo lugar, que tem as características próprias para a captação e difusão mediante [o uso de] imagens e/ou sons". Assim, o audiovisual, enquanto informação e objeto-documento, captura, testemunha e funciona como fonte documental, seja de forma objetiva, a exemplo de um documentário (para o cinema ou televisão), ou mesmo subjetivamente, numa produção ficcional. 
Essas duas percepções do objeto-documento têm características e finalidades distintas, pois, enquanto o documentário objetiva ser uma captura do real com menos interferências, o audiovisual ficcional, ainda que também busque ser um retrato da realidade ou de apresentar esse real transfigurado dentro de um recorte, possui elementos reais misturados aos ficcionais, como identificado nos filmes, séries, minisséries e telenovelas. Esta é uma ponderação que necessita ser esclarecida na escolha, seleção e apresentação do audiovisual como documento. Ao focalizar a temática da documentação, compreende-se que a mesma é vista como o conjunto de documentos que agregam fontes de informação registradas das e nas sociedades e tem demonstrado a falta de uma contemplação de modelos e tipos documentais para além dos documentos textuais. Percebe-se, portanto, que há um silenciamento e esquecimento (proposital ou deficitário) no decorrer da história dos documentos, particularmente sobre os documentos audiovisuais. Este cenário pode ser vislumbrado na escassez da produção científica na cobertura da temática em discussão.

Conforme Tartaglia e Butruce (2015, p. 331) "[...] assim como a fotografia, os registros audiovisuais só ultimamente passaram a ser compreendidos como documentos e reconhecidos como patrimônio a ser preservado e divulgado". Este fato, segundo as autoras, está relacionado com a existência de duas publicações: a) "Recomendação para a salvaguarda e preservação das imagens em movimento", um documento produzido pela Organização das Nações Unidas para a Educação, a Ciência e a Cultura (Unesco), em 1980 e; b) a obra de Ray Edmondson "Audiovisual archiving: philosophy and principles", em 1998. Além disso, mesmo não adentrando ao escopo desta pesquisa, mas por possuir um caráter científico e acadêmico de grande contribuição para esta pesquisa, destacam-se dois livros: "O que é documentação" de autoria de Johanna Smit ${ }^{1}$, um clássico dedicado ao assunto; e "O que é a documentação" de autoria de Suzanne Briet ${ }^{2}$.

Deste modo, observa-se que, apenas a partir da década de 1980, tem-se um documento, uma formalização da necessidade de atenção e preservação com esse modelo documental criado pela Unesco. E, na década de 1990, uma publicação em caráter científico que dialoga diretamente com a temática da documentação audiovisual apresentada por Edmondson, o que demonstra a construção de uma literatura recente sobre a área e ainda carente de aprofundamento. Assim, é frente a esta percepção que este estudo se debruça com o intuito em contribuir para o campo da documentação audiovisual, oportunizando um protagonismo que lhe foi negado e identificando a produção científica sobre a temática existente. Essa negação é visualizada quando se averigua uma demasiada produção intelectual sobre os documentos físicos e, ao contrário, uma produção científica sobre o audiovisual nos estudos da Biblioteconomia, por exemplo, mesmo esse tipo de documento não sendo recente. Possivelmente, esse fato seja efeito tanto de uma discussão teórica ainda incipiente e em construção, quanto da falta de documentos audiovisuais nos ambientes informacionais, fazendo com que o profissional da informação se distancie desse modelo documental em seus processos de representação, tratamento, gestão, entre outros. Além disso, a própria produção do audiovisual demandava um custo alto frente a pouca tecnologia da época e deve ser um elemento considerado na reflexão para a sua ausência em tais ambientes.

Com isso, entende-se que a problemática da documentação audiovisual perpassa os territórios da Ciência da Informação (CI) e das Ciências da Comunicação (CC), enquanto temáticas de pesquisa acerca do material audiovisual. Na CI, o audiovisual está atrelado aos processos de organização e representação e, na CC, com a construção e a produção desse conteúdo audiovisual (documentários para o cinema, televisão ou internet; programas de televisão ou internet; gravação de conferências, palestras e/ou eventos no geral, por exemplo). De tal modo, a compreensão da produção científica em tais campos sobre a documentação audiovisual permite visualizar essa paisagem de exploração de um campo e objeto ainda pouco investigado.

Dentro deste escopo, tem-se como hipótese uma conjuntura de pesquisas e publicações acadêmicas que se debruçam sobre o campo da Documentação, podendo ser denominado como clássico, ao objetivar investigar os documentos textuais em detrimento de um corpo científico e prático pouco identificado como o arcabouço documental audiovisual. Assim, este estudo objetiva identificar as produções existentes acerca da temática da documentação, visualizada como um campo ainda pouco explorado cientificamente, quando comparado a outros campos e abordagens documentais na Ciência da Informação e Ciências da Comunicação. Como objetivos basilares: a) coletar a produção científica a partir dos eixos: artigo de anais, artigo de periódico, dissertação e tese e b) analisar a datificação e a área de concentração das produções científicas identificadas.

Os procedimentos metodológicos são construídos a partir da abordagem quanti-qualitativa e do uso da estratégia de pesquisa exploratória-descritiva para a avaliação e o aprofundamento diante das informações disponíveis na tentativa de explicar o contexto do fenômeno em questão. Para isso, vale-se das publicações realizadas em formatos de artigos de anais de evento, artigos de periódicos, dissertações e teses. A partir desta coleta, delimitou-se o recorte temporal de 1984 a 2019, mediante os dados encontrados na pesquisa quantitativa. O ano de 1984 foi selecionado em razão de ser o primeiro ano da década de 1980 que apresenta um dos modelos de documentos delimitados para este estudo, um artigo de periódico.

\footnotetext{
${ }^{1}$ Smit, J. W. (1986). O que é documentação. São Paulo: Brasiliense.

${ }^{2}$ Briet, S. (2016). O que é documentação? Tradução de Maria de Nazareth Rocha Furtado. Brasília, DF: Briquet de Lemos.
} 


\section{BREVE HISTÓRICO DA DOCUMENTAÇÃO AUDIOVISUAL}

No campo da Biblioteconomia e Ciência da Informação (BCI) a documentação audiovisual, de modo geral, é marcada por silenciamentos e esquecimentos ao longo da sua história numa comparação com a visualização da documentação em caráter textual. Considerado como um documento especial (Buarque, 2008), o documento audiovisual fruto deste campo documental, passou a fazer parte das coleções como um apêndice dos ambientes informacionais. Esta primeira identificação e observação é fundamental acerca da documentação audiovisual, pois fortalece a necessidade de discutir de forma mais aprofundada a temática no século XXI.

Um dos aspectos que deve ser considerado neste cenário é a falta de uma política audiovisual (Almeida, Reis, \& Silva, 2019) que explicite a importância e a necessidade desses documentos audiovisuais para a sociedade em caráter documental, político - pois, tal formalização sugere uma "fortificação" do seu caráter histórico e a necessidade de preservação. Como relata Buarque (2008, p. 2):

Não era incomum verificar, até há alguns poucos anos, que grande parte dos arquivos, bibliotecas, centros de pesquisa e instituições de guarda em geral, tratavam de classificar filmes e fitas como sendo 'documentos especiais', evidenciando uma dificuldade em identificar as particularidades e características desses documentos.

O apontamento feito por Buarque em 2008, pouco mais de uma década atrás, já evidenciava a necessidade da problematização dos acervos e arquivos audiovisuais, seja por uma visibilidade, nomenclatura ou compreensão das suas próprias marcas enquanto documento. Inicialmente, parece ser uma constatação clara que o documento audiovisual possui sua própria identidade: a salvaguarda em um suporte diferenciado dos demais e o uso de dispositivo de acesso para a sua reprodução. Contudo, faz-se preciso abordar essas questões como forma de ascender e tecer algumas questões basilares sobre o objeto de estudo. Essa mesma perspectiva é observada por Edmondson (1998, p. 3), ao dizer que

[...] a filosofia de arquivos audiovisuais pode ter muito em comum com a de outras profissões afins, mas preconiza-se que deve surgir da natureza dos documentos audiovisuais, e não por analogia automática com essas profissões. Igualmente, a intenção foi tentar descrever os documentos audiovisuais em termos do que são, em lugar do que não são, e consequentemente evitar frases como 'não livro', 'não texto' ou 'materiais especiais'.

Essa denominação reside na onipresença do documento textual na sociedade e nas práticas de organização, representação e preservação estarem voltadas para este tipo documental no contexto histórico e científico. Assim, tudo o que não era classificado como documento textual, era concebido como documento especial. Além disso, o documento audiovisual tem algumas particularidades como a necessidade de um dispositivo de acesso, o que demanda atenção para a obsolescência desses dispositivos e a necessidade de uma migração para novos suportes. E, também, de características multimidiáticas: textual, iconográfica e sonora.

O apontamento dessas características sobre o documento audiovisual é pertinente, pois elas constroem o percurso da informação, especificamente desse formato, e produto informacional. A partir da presença da multimidialidade, como aponta Salaverría (2014), dialoga-se com a recepção da informação de modo multissensorial, uma vez que esta é a mesma forma de nos comunicarmos. Com isso, a presença dos sentidos da audição e visão conjuntamente no documento audiovisual elevam o processo infocomunicacional, desenvolvendo uma percepção que explora os diversos sentidos para a compreensão da mensagem.

Para Tauil e Simionato (2016), o tratamento do documento audiovisual não é totalmente contemplado pela Biblioteconomia. Frente a essa explanação, é preciso considerar dois aspectos: 1) como já referido acima, o histórico da presença de documentos textuais e 2) a discussão e a pesquisa científica que são recentes sobre os documentos audiovisuais, como identificada ocorre a partir da década de 1980 no Brasil - visualizada no processo de levantamento referencial sobre o tema pelo pesquisador.

Assim, considera-se como uma das pesquisadoras propulsoras sobre documento audiovisual no Brasil a professora Johanna Wilhelmina Smit, da Universidade de São Paulo, já aposentada, que ministrava disciplinas voltadas para a documentação audiovisual e possui publicações científicas sobre o tema a partir da década de 1980. E, como uma das primeiras pesquisas sobre o audiovisual no campo da Biblioteconomia, a destacar a importância e necessidade da incorporação deste documento na biblioteca, a pesquisa "Materiais audiovisuais na sociedade e nas bibliotecas brasileiras" de Cavan Michel McCarthy e Targino e Maria das Graças Targino de 1984. Deste modo, Lima (2016) explica que esse arcabouço acerca do audiovisual no campo da Biblioteconomia está relacionado à diversidade de dispositivos (películas fílmicas, fitas diversas como a quadruplex, U-matic, Beta, VHS etc.) de armazenamento da informação audiovisual. Assim,

Essa diversidade durante muito tempo fez com que a documentação audiovisual fosse vista como um problema em um sistema padronizado regido por regras rígidas como o das bibliotecas tradicionais. Por esse motivo, esses documentos acabavam relegados a um setor muitas vezes denominado de especial, mas sem efetivo planejamento para sua inserção no sistema de recuperação de informação 
das instituições (Lima, 2016, p. 87).

Diante dessa realidade, o acervo audiovisual adquire maior respaldo e visibilidade com o próprio desenvolvimento da sociedade, dos artefatos e dos dispositivos de produção de imagem, que se intensificaram no século XX, visto que os primeiros arquivos de filmes datam de pouco mais de um século (Menezes, 2019). Assim, “[...] o crescimento desse material ampliou a percepção de um problema que já existia, mas que era restrito a discussões em sistemas de informações bem específicos, como os de Arte e Comunicação" (Lima, 2016, p. 87). E, que necessita de uma amplificação na conjuntura atual, objetivando questões em diversos âmbitos como preservação, produção, propostas de representação, interfaces analógicas e digitais de uso e acesso à informação, entre outras vertentes.

Nesta perspectiva altera-se o trato com o acervo e o documento audiovisual na temática da informação, em seus mais diversos formatos e suportes: sobretudo da informação audiovisual. Saracevic (1996) observa que essa relação vem sendo remodelada com o decorrer do tempo, a partir da introdução desses outros tipos de documentos de forma mais abrangente na sociedade. Desse modo, há uma necessidade de explanar de forma científica sobre esse objeto de estudo, visto que, atualmente, tem-se um alargamento da produção de documentos audiovisuais na sociedade contemporânea.

Neste sentido, Nuno (2012) explica que a documentação audiovisual foi sendo incorporada e ganhando espaços nas instituições, sobretudo em instituições de Comunicação:

Os Arquivos Audiovisuais e Sonoros foram constituídos a nível interno pelas instituições de comunicação, nunca dispondo de uma grande autonomia no interior das organizações. Na verdade, foram emergindo de forma difusa, em parte sob os auspícios de uma larga variedade de instituições de recolha, instituições académicas e outras, como uma extensão natural do seu trabalho. Só a partir dos meados do século XX, se assistiu à organização das primeiras associações internacionais, reconhecidas como organismos de Arquivo e Biblioteca. Por exemplo, o advento da IASA (International Association of Sound and Audiovisual Archives) e da FIAT (Federation International Archives Television) surgiu da necessidade de os profissionais partilharem experiências no plano técnico (Nuno, 2012, p. 158).

Esta percepção ancora-se na explicitação de Menezes (2019, p. 85-86) em que "[...] a atividade de preservação audiovisual é relativamente nova [...]. A área de preservação audiovisual passa por um processo de amadurecimento, com início nos anos 2000". Com isso, é preciso considerar alguns aspectos sobre os arquivos audiovisuais, que estão em consonância com o Plano Estratégico Patrimonial (PEP) elaborado como parte do Programa Mercosul Audiovisual (PMA). Assim, Bezerra e da Silva Santos (2019) destacam três elementos:

a) A operação historiográfica realizada por arquivos e cinematecas;

b) Os arquivos organizados internacionalmente desde 1938, quando da criação da Federação Internacional dos Arquivos Fílmicos (FIAF);

c) As crises e a falta de recursos institucionais. Elementos que corroboram para explicar as dificuldades e descaso com desses arquivos e documentos audiovisuais.

Essa visualização acerca da documentação audiovisual deve ser fortalecida não somente pelas instituições como a FIAF, o PMA e o próprio PEP, que são instituições com a finalidade de proteger esse patrimônio. Mas, da investigação e produção científica sobre esta temática, bem como a participação em eventos que propiciem espaços para o debate, apresentação de trabalhos, trocas informacionais e que oportunizem o protagonismo social do documento audiovisual, seja no campo da CI ou CC.

\section{INFORMAÇÃO, ARQUIVO E DOCUMENTO AUDIOVISUAL}

Ao dialogar sobre a documentação audiovisual no campo da CI e CC, entende-se que é necessário abordar as temáticas bases que congregam e estabelecem este tipo de documento. Assim, tem-se o tripé informação, arquivo e documento apresentando uma definição destes conceitos, não de forma exaustiva, visto que este não se configura enquanto o objetivo da pesquisa, mas enquanto fundamentação teórica da discussão sobre o objeto em análise.

Adota-se como conceito de informação para esta pesquisa a seguinte definição: "[...] a informação é um conhecimento inscrito (gravado) sob a forma escrita (impressa ou numérica), oral ou audiovisual e em um suporte" (Le Coadic, 1994, p. 5). Este conceito perpassa o diálogo com o campo da documentação audiovisual. De acordo com Hernández-Alfonso (2007), a informação audiovisual é o conjunto de mensagens cujo conteúdo é basicamente representado por imagens em movimento, acompanhado, ou não, de forma síncrona por elementos do sistema de som (vozes, música, ruído).

O uso do conceito de informação de Le Coadic (1994) é fundamental por considerar a informação em seus mais diversos suportes, rompendo com a ideia de informação apenas em documentos textuais. Assim, a informação audiovisual, em sua essência, parte da tessitura textual, visual e sonora (Joly, 2012; Primo \& Cabral, 2014; Rose, 2015) cujo objetivo é transmitir a informação. Essa transmissão ocorre através de uma produção documental 
que, conforme explica Buckland (1997), passou a visualizar nas imagens gráficas, fotográficas e audiovisuais uma nova possibilidade de tipos de documento e informação.

Mas, o que é o arquivo? De acordo com Rodrigues (2006, p. 105), "[...] arquivo é um conjunto de documentos produzidos e recebidos no decurso das ações necessárias para o cumprimento da missão predefinida de uma determinada entidade coletiva, pessoa ou família". Neste sentido, tem-se a compreensão de arquivo como uma instituição, departamento ou lugar (seja físico ou digital, a partir das novas possibilidades advindas com as novas tecnologias da informação), que congrega e reúne os documentos, visando a salvaguarda, gerenciamento, recuperação e disseminação da informação.

Visualiza-se, assim, uma sociedade marcada pela obsessão da memória na qual a produção dessas imagensmemória a serem arquivadas e preservadas se apresentam ao sujeito em suportes materiais (Colombo \& Borges, 1991). Neste sentido, o arquivo funciona como um lugar em que se torna possível a localização dessas memórias audiovisuais, como as emissoras de televisão, especificamente o telejornalismo, já fazem para armazenar e acessar os arquivos de imagens do telejornal. Já acerca o documento é

[...] o repositório de um pensamento expresso. Consequentemente, seu conteúdo tem um caráter espiritual. O perigo de que a unificação abrupta da forma externa exerça uma repercussão no conteúdo, tornando a última sem caráter e impessoal, não é ilusória. Ao padronizar a forma e o layout dos documentos, é necessário restringir essa atividade àquela que não afeta o conteúdo espiritual e que serve para remover uma variedade realmente irracional (Donker-Duyvis, 1942, p. 48, tradução nossa $)^{3}$.

E, conforme Otlet (1934, p.10, tradução nossa), o documento é “[...] o registro do pensamento humano e da realidade exterior em elementos de natureza material [...] um suporte de uma certa matéria e dimensão [...] em que se incluem signos representativos de certos dados intelectuais" 4 . O autor propõe que "documento" seria um termo genérico que cobriria não apenas documentos textuais, mas, também, objetos iconográficos e audiovisuais. Assim, um documento audiovisual é a apresentação do conteúdo informacional registrado noutro suporte e que necessita de um dispositivo eletrônico de acesso como, por exemplo, um pen drive precisa estar conectado em um computador ou aparelho de TV para que o seu conteúdo seja acessado ou, ainda, sendo arquivado em "nuvem" e sendo acessado sob o uso de um artefato tecnológico.

Para Santana (2019, p. 16) os documentos audiovisuais "[...] constituem em provas de fatos ocorridos, sendo na maioria das vezes, vistos como a própria realidade fixada no suporte", pois essas imagens, posteriormente transformadas em documentos, são visualizadas como índices de representação do real "[...] ou em algumas situações consideradas como a própria realidade materializada em suportes físicos e digitais" (Santana, 2019, p. 17-18). Nesta perspectiva e, vislumbrando uma compreensão visual do que foi exposto, a Figura 1 apresenta uma estrutura da documentação audiovisual e explicita a função do campo da CI e da CC, respectivamente:

\footnotetext{
${ }^{3}$ Tradução nossa a partir do texto original do autor: "[...] de bewaarplaats van een uitdrukkelijke gedachte. Bijgevolg heeft de inhoud een spiritueel karakter. Het gevaar dat de abrupte eenwording van de externe vorm gevolgen zal hebben voor de inhoud, waardoor deze karakterloos en onpersoonlijk wordt, is niet illusoir. Bij het standaardiseren van de vorm en lay-out van documenten, is het noodzakelijk om deze activiteit te beperken tot datgene wat de spirituele inhoud niet beïnvloedt en dat dient om een echt irrationele variëteit te verwijderen" (Donker-Duyvis, 1942, p. 48).

${ }^{4}$ Tradução nossa a partir do texto original do autor: "L'enregistrement de la pensée humaine et de la réalité extérieure en éléments de nature matérielle (...) un support d'une certaine matière et dimension (...) dans lequel sont inclus des signes représentant certaines données intellectuelles" (Otlet, 1934, p.10)).
} 


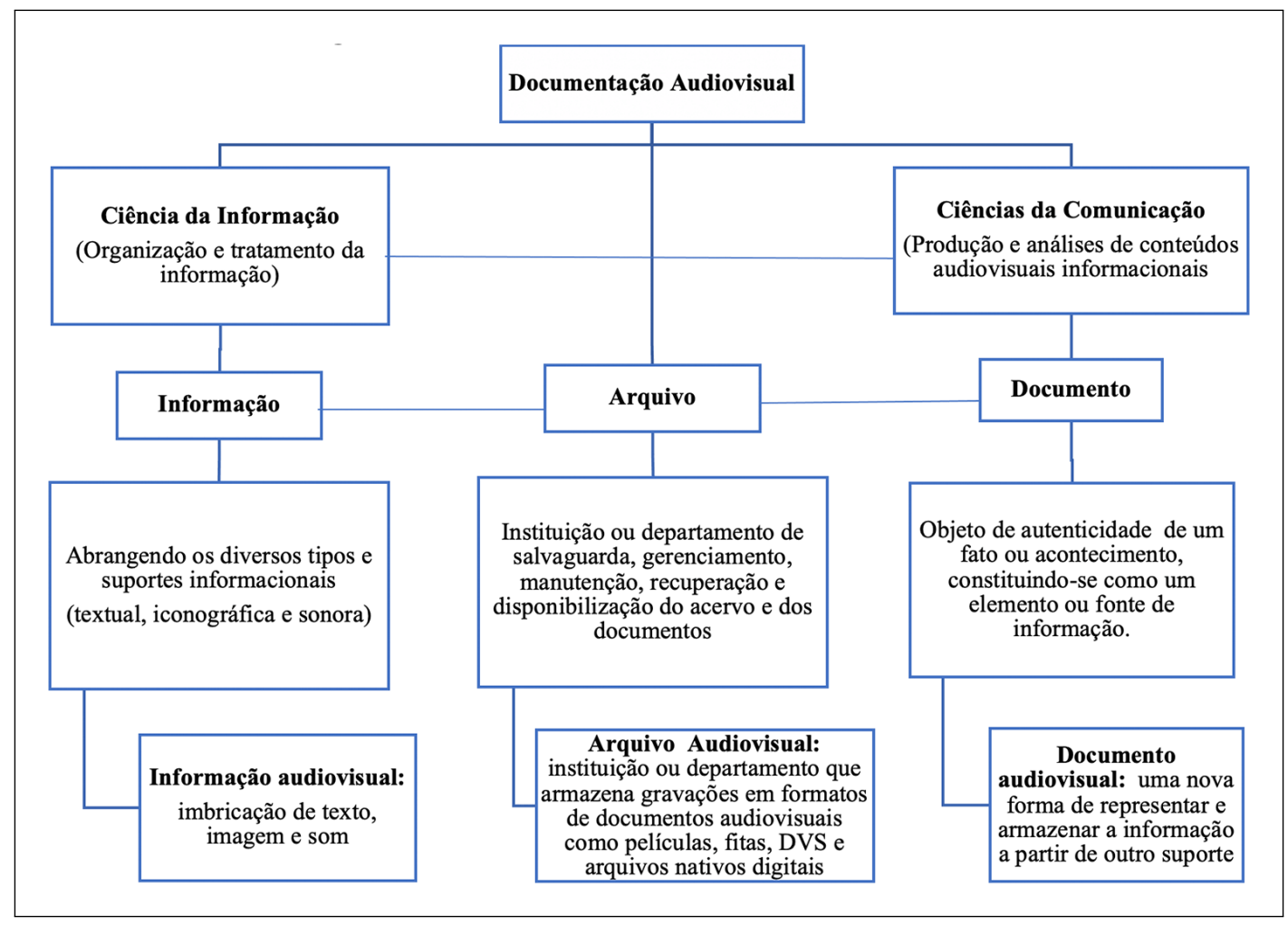

Figura 1. Estruturação da documentação audiovisual.

Fonte: Elaborado pelo autor (2020)

Deste modo, é possível compreender e estabelecer as conexões entre os campos e as áreas, partindo do geral para o específico. E, com isso, visualizando as dinâmicas que envolvem o campo da documentação audiovisual na CI e CC, uma vez que esta estruturação possibilita a identificação das principais temáticas exploradas neste artigo e orienta leitores e pesquisadores a compreenderem os pontos centrais da discussão.

\section{PROCEDIMENTOS METODOLÓGICOS}

A metodologia adotada para este estudo é construída a partir de uma abordagem quanti-qualitativa, frente ao levantamento dos dados sobre publicações científicas acerca da temática que contempla a documentação audiovisual no campo da Ciência da Informação e Ciências da Comunicação. Minayo e Sanches (1993) explicam que nesta abordagem o pesquisador está diante dos problemas de modo objetivo e subjetivo, podendo dialogar entre essas duas esferas diante com o objeto de estudo.

O estudo faz uso do estudo exploratório-descritivo Gil (2008). Enquanto o primeiro almeja um aprofundamento do objeto e a familiarização do pesquisador com o tema, o segundo perpassa pelo detalhamento, pormenorização das observações e inferências sobre o objeto em análise - assim, diante do percurso exploratório e da coleta dos dados, posteriormente, será possível inferir sobre o circuito científico brasileiro.

A coleta dos dados deu-se a partir da seguinte categorização: artigos de anais (AA), artigos de periódicos (AP), dissertações (D) e teses (T). A coleta ocorreu em anais de eventos nacionais: a Sociedade Brasileira de Estudos Interdisciplinares da Comunicação (Intercom), o Encontro Nacional de Pesquisa em Ciência da Informação (Enancib) e em revistas científicas brasileiras da Informação e Comunicação, a partir de bases de dados como o Banco Digital de Teses e Dissertações (BDTD), SciELO e Periódicos Capes. Para uma busca mais refinada, foram utilizados os seguintes descritores: "arquivo", "documento", "informação" em consonância com o termo "audiovisual". O período de recorte dá-se entre 1984 a 2019, vislumbrando desde a primeira publicação nacional visualizada até as mais recentes (com disponibilização anual completa das publicações). Assim, foram identificadas um total de 28 produções científicas que serão analisadas a seguir.

\section{DISCUSSÃO SOBRE A DOCUMENTAÇÃO AUDIOVISUAL}

Diante da coleta dos dados, visualizou-se que essas 28 produções científicas, contemplando a temática da documentação audiovisual nos campos da CI e da CC, estão categorizadas nas seguintes modalidades de pesquisa (Figura 2) a seguir: 


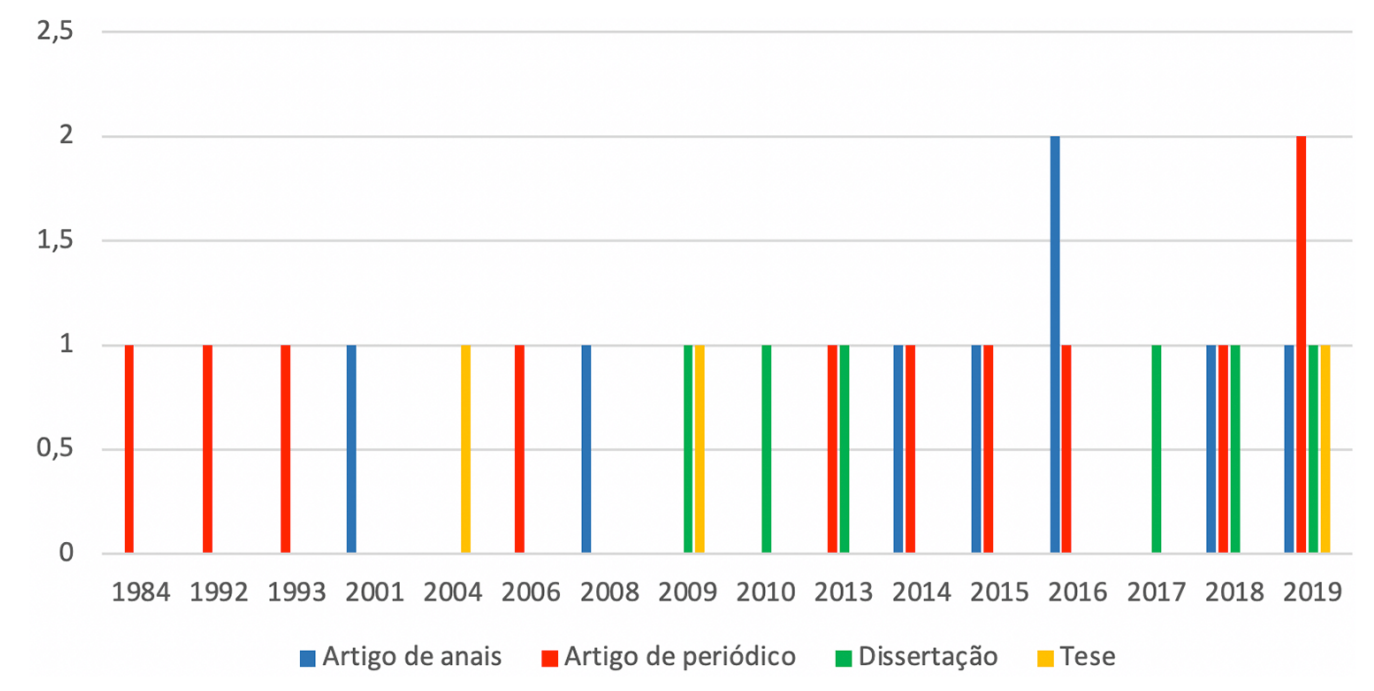

Figura 2. Quantidade de publicações científicas por categoria e ano. Fonte: Elaborado pelo autor (2020)

Essa categorização foi estabelecida por tipo de publicação e ano, a partir de uma linha cronológica dos dados coletados. Neste primeiro momento, a produção científica não está organizada por área de concentração, mas apenas por quantificação de 1984 (ano da primeira publicação) ${ }^{5}$ até o ano de 2019 - considerando as áreas da CI e CC. Percebe-se que há uma linearidade quantitativa em sua maioria, rompida apenas nos anos de 2016 e 2019 , em que se verificam quatro produções científicas, sendo duas AA em 2016 e duas AP em 2019. Essa linearidade apresenta-se como negativa dentro do atual contexto, no sentido em que se observa a pouca exploração sobre o tema. De 1984 a 2015, as publicações não ultrapassam a quantidade de uma publicação por categoria, tendo no máximo a existência de duas publicações por ano, mas em categorias diferentes.

Além disso, visualiza-se que há espaçamentos temporais que vão se modulando como, por exemplo, a primeira publicação, que surge na década de 1980 e somente ressurge no início da década de seguinte, em 1990. Desse modo, da primeira para a segunda publicação tem-se um espaço de oito anos, um tempo consideravelmente longo dentro do recorte, analisando AA, AP, D e T. Esse mesmo recorte temporal ocorre entre os anos de 1993 a 2001 e, a partir do ano de 2004, identifica-se uma presença mais constante de pesquisas sobre o tema, sendo vislumbrada uma maior quantificação de pesquisa até o ano de 2019. Assim, observa-se uma assiduidade das publicações a partir do ano de 2013 até 2019, com 18 publicações.

É interessante ressalvar que a primeira publicação, diante do recorte do corpus analisado, só ocorre em 1984, visto que a atividade da documentação não é recente no Brasil e data do final do século XIX ${ }^{6}$. Isso, de modo geral, confirma a hipótese previamente levantada: há uma conjuntura de pesquisas e publicações acadêmicas que se debruçam sobre o campo da Documentação textual em detrimento de um corpo científico e prático pouco identificado e refletido do arcabouço documental audiovisual. Diante destes dados, compreende-se a existência de uma baixa produção teórica e intelectual sobre a documentação audiovisual, refletindo na dificuldade do aprofundamento histórico e epistemológico do campo de pesquisa tanto na CI como na CC - impactando no próprio ato do fazer científico. Assim, buscou-se expor a quantificação das produções científicas sobre documentação audiovisual na área da CI e CC (Figura 3):

\footnotetext{
${ }^{5} \mathrm{~A}$ primeira publicação sobre a documentação audiovisual é intitulada "Materiais audiovisuais na sociedade e nas bibliotecas brasileiras", dos autores Cavan Michael Mccarthy e Maria das Graças Targino.

${ }^{6}$ Ortega, C. D. (2009). Surgimento e consolidação da documentação: subsídios para compreensão da história da Ciência da Informação no Brasil. Perspectivas em Ciência da Informação, 14(esp.), 59-79. Recuperado de https://www.scielo.br/pdf/pci/v14nspe/a05v14nspe.pdf
} 


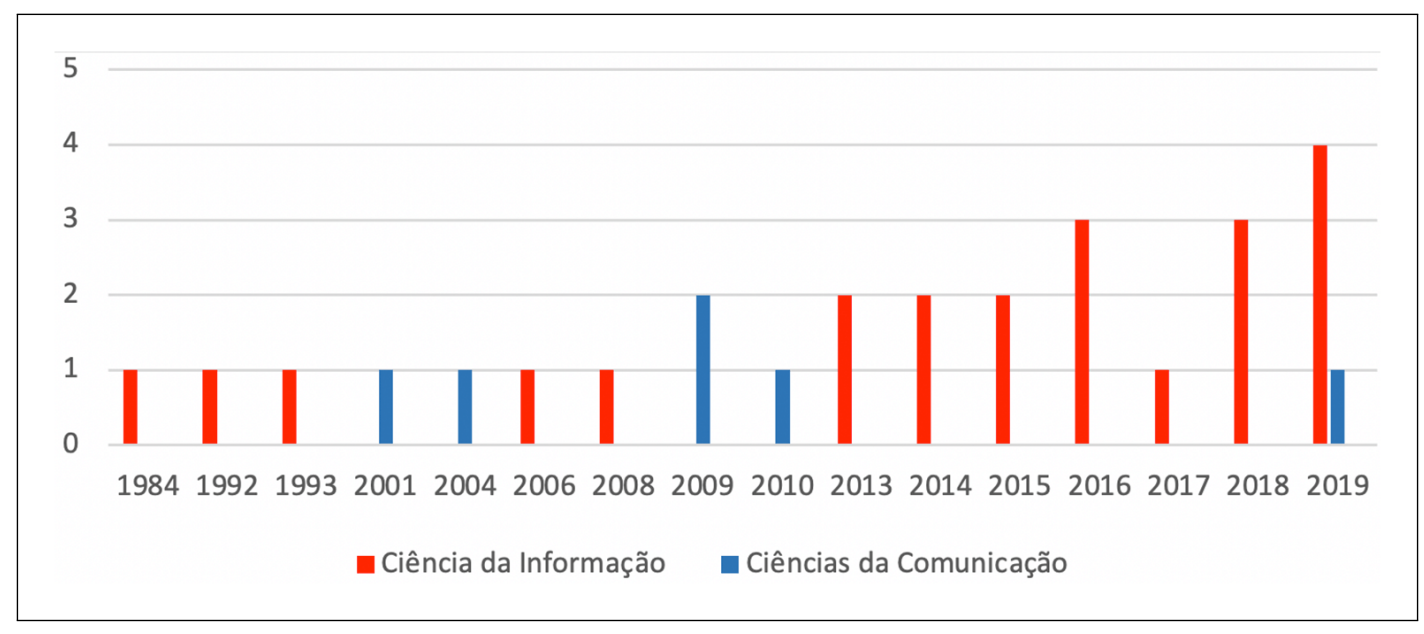

Figura 3. Quantidade de publicações científicas por área. Fonte: Elaborado pelo autor (2020)

Uma vez que o campo da Documentação se aproxima mais do universo da Ciência da Informação ${ }^{7}$, frente à disciplina da Biblioteconomia no Brasil e Documentação na Espanha, por exemplo, os dados coletados demonstram a supremacia de pesquisas no campo da CI em relação ao campo de estudos da CC. A demonstração de tais dados frente à representação na Figura 1, explica que a CI está mais propensa no que concerne às atividades de organização e representação da informação e tratamento de documentos e, assim, pode ser atribuída essa menor quantificação em relação à CC, que está mais voltada para a produção desses documentos audiovisuais. Tal fato não exclui a possibilidade das Ciências da Comunicação adentrarem no território simbólico de conhecimento sobre o objeto de estudo, como demonstrado na quantificação das produções científicas por área e categoria (Tabela 1):

\begin{tabular}{lcccc}
\hline Área de concentração & AA & AP & D & T \\
\hline Ciência da Informação & 7 & 11 & 3 & 1 \\
\hline Ciências da Comunicação & 1 & 1 & 2 & 2 \\
\hline
\end{tabular}

Tabela 1. Quantificação da produção científica por área e categoria.

Fonte: Elaborado pelo autor (2020)

A CI tem no total 22 produções científicas, contemplando a área da documentação audiovisual e a CC, 6 produções. Na pós-graduação stricto sensu, ou seja, nos cursos de mestrado e doutorado, ressalta-se a visualização de um menor número de produções dentro do escopo de categorias analisadas: na CI, três dissertações e uma tese; e, na CC, duas dissertações e duas teses. Ou seja, ao considerar a dissertação e a tese como produções de maior respaldo acadêmico - por serem pesquisas com aprofundamento e reflexão mais elevados e nas quais a avaliação ocorre mediante uma banca formada por professores doutores -, não são grandes números que contemplam o universo da documentação audiovisual na pós-graduação. O maior número de pesquisas está contemplado pelos artigos de periódicos na CI com 11 artigos e, em seguida, com os artigos de anais, com sete produções científicas. Já na CC, os números são bem inferiores quando comparados com a CI (ver Tabela 1). Esse fenômeno pode ser interpretado mediante ao que já foi destacado neste estudo: o caráter analítico sobre os processos de preservação, representação e recuperação de documentos da Ciência da Informação; e a preocupação em produzir e analisar os conteúdos informacionais a partir das Ciências da Comunicação.

Não é fácil a tarefa de identificar os motivos e as razões, ao menos inicialmente, com esta pesquisa, da baixa incidência sobre a documentação audiovisual enquanto objeto de investigação dessa CI e CC. O que pode ser feito, neste momento, são algumas conjecturas, frente ao próprio processo histórico de construção particularmente na BCI. Como explicitado no referencial teórico, visualiza-se a supremacia do documento textual e a pouca familiarização dos profissionais com documentos de outros formatos e suportes, tendo as primeiras publicações na década de 1980.

Acerca das abordagens, percebe-se uma recorrência entre elas: a) o uso do material audiovisual em bibliotecas; b) políticas de preservação de acervos; c) estudos de caso de instituições que possuem acervos audiovisuais; d) documentação audiovisual de empresas jornalísticas; e) organização e representação de acervos audiovisuais; f) memória de documentos audiovisuais; g) gestão documental audiovisual e; h) processo de digitalização de documentos audiovisuais.

\footnotetext{
${ }^{7}$ Essa afirmação é decorrente da percepção de que a Ciência da Informação está mais próximo dos estudos de representação, salvaguarda e recuperação da informação contida nos documentos audiovisuais. Por outro lado, as Ciências da Comunicação volta a sua atenção para o âmbito da produção e análise desses conteúdos informacional.
} 
Deste modo, mesmo diante da baixa produtividade científica que versa sobre o tema, as pesquisas apresentam uma multiplicidade e diversidade de temáticas e abordagens sobre a documentação audiovisual no Brasil. Isso não significa que estes estudos contemplam todos os aspectos, pois, como observado, visualizam-se poucos estudos acerca do caráter histórico e epistemológico; de uma discussão mais aprofundada sobre as políticas de preservação; de acervos audiovisuais para além de instituições já conhecidas como a Cinemateca Brasileira ou as empresas jornalísticas, por exemplo.

Neste sentido, as pesquisas visualizadas no âmbito da Ciência da Informação contemplam as três disciplinas que pertencem a este campo: Arquivologia, Biblioteconomia e Museologia. Há uma identificação das atividades de organização da informação em tais áreas. Assim, a documentação audiovisual perpassa essas três realidades. Já no campo das Ciências da Comunicação, o objeto de estudo perpassa a realidade do Jornalismo na produção e confecção de conteúdos audiovisuais que, posteriormente, se transformam em documentos a serem preservados. A realidade com a preocupação desses documentos na CC ocorre mediante a produção jornalística nas emissoras de televisão que, em seu Centro de Documentação (Cedoc), já realizam atividades de preservação da memória audiovisual.

\section{CONSIDERAÇÕES FINAIS}

Os campos do conhecimento de investigação desta pesquisa, CI e CC, demonstraram que a produção científica acerca da documentação audiovisual ainda é incipiente, seja em seu caráter quantitativo ou qualitativo, a partir de um estudo exploratório-descritivo sobre as abordagens e temáticas identificadas. As produções científicas identificadas no período de 1984 a 2019, totalizando 28 produções, servem como dados e estatísticas para explicitar essa constatação. Acerca deste objeto de estudo, pode-se inferir que a) houve ao longo do tempo um esquecimento e silenciamento, sobretudo na CC, desses registros audiovisuais enquanto fontes de informação; b) que está relacionado com o contexto histórico no qual os ambientes de informação, sobretudo a biblioteca, era um lugar repleto de documentos em caráter textual e, c) apenas posteriormente com a introdução de novas linguagens e suportes informacionais tem-se a presença de documentos em formatos diferenciados, os chamados "documentos especiais"

Essa sinalização aponta para uma necessidade de expansão da pesquisa, investigação e discussão da temática sobre os documentos audiovisuais na sociedade. Dessa forma, será possível a construção de um corpus teórico-reflexivo maior e mais aprofundado e, podendo contextualizar o caráter histórico. Assim, a documentação audiovisual perpassa esse lugar pouco explorado pela CI e CC, como averiguado, com a coleta de dados sobre a produção científica a partir de artigos publicados em artigos de anais de eventos, artigos de periódicos, dissertações e teses de programas de pós-graduação. O recorte temporal (1984 a 2019) evidencia que há um deslocamento e crescimento, ainda que pouco, de estudos contemplando este objeto de estudo, particularmente na CI, porém sinalizando positivamente para um aumento.

Contudo, ainda apresenta baixa representatividade quantitativa frente ao campo da documentos em caráter textual, mesmo que os documentos audiovisuais estivessem contemplados na área como salientou Paul Otlet, em 1934. Esse retrato acarreta na observação do momento histórico, cultural e tecnológico, que dificultava a produção massiva do audiovisual e que, somente com o barateamento dos equipamentos, sejam profissionais ou caseiros, chegando à realidade atual dos dispositivos móveis, é que se averigua uma expansão em larga escala dessa linguagem informacional. Uma realidade que passou pelo cinema, adentrou a televisão e perpassa o uso das novas mídias, suas ferramentas e plataformas on-line.

Como observado na Figura 1, em termos de quantidade de produção por ano, diante cada categoria, a realidade pouco foi alterada, sendo possível somente a visualização de produções científicas por mais um de categoria no mesmo ano em 2009, de 2013 a 2016 e 2018 e 2019. Nestes dois últimos anos, enxerga-se ao menos três produções contemplando as diferentes categorias. Foi possível apontar também que as pesquisas a nível de pós-graduação sobre a documentação audiovisual são pouco visualizadas, mas elas perpassam tanto o campo da CI como da CC.

Nesta perspectiva, a documentação audiovisual é um território convidativo para pesquisadores proporem estudos e abordagens históricas, sociais, culturais, políticas e tecnológicas do objeto de estudo, uma vez que o audiovisual tem sido ampliado na sociedade e utilizado como prova documental ou como objetivo de rememoração como: o uso de imagens de arquivo para contextualizar um acontecimento atual; a produção de documentário e filmes que se utilizam das imagens arquivadas para elaborar a narrativa; documentos audiovisuais que possibilitam identificar a memória de uma instituição ou sujeito específico dentre outros casos. Ainda que esse processo já pudesse ser visto com arquivos fotográficos, por exemplo, os arquivos e documentos audiovisuais têm sido cada vez presentes no cotidiano da sociedade e apresentam uma visão mais processual do registro informacional, perante o caráter multimidiático, assim, a informação se apresenta de forma textual (verbal), iconográfica (imagem) e sonora (auditiva).

\footnotetext{
${ }^{8}$ De acordo com Bellotto (1991), os documentos audiovisuais são assim denominados por apresentares características que os diferencia dos demais (os textuais). Além, da necessidade do uso de um dispositivo de reprodução para a sua visualização. Informação disponível em: Bellotto, H. L. (1991). Arquivos permanentes: tratamento documental. São Paulo: T. A. Queiroz Editor.
} 


\section{REFERÊNCIAS}

Almeida, M., Reis, A. L., \& Silva, A. M. d. C. (2019, maio ). Acervos Audiovisuais em um Museu de História das Ciências. Museologia $\&$ Interdisciplinaridade, 8(15), 138149. Recuperado de https://doi.org/10.26512/museologia .v8i15.24672 doi: 10.26512/museologia.v8i15.24672

Bezerra, L., \& da Silva Santos, J. (2019). Diversidade cultural e a preservação de acervos audiovisuais do eixo sul. RELACult-Revista Latino-Americana de Estudos em Cultura e Sociedade, 5(esp.), 1-16.

Buarque, M. D. (2008). Estratégias de preservação de longo prazo em acervos sonoros e audiovisuais. In Anais do ix encontro nacional de história oral. São Leopoldo: UNISINOS.

Buckland, M. K. (1997). What is a "document"? Journal of the American society for information science, 48(9), 804809 .

Cebrián-Herreros, M. (2007). Información audiovisual: concepto, técnica, expresión y aplicaciones (segunda reimpressão). Madrid: Síntesis.

Colombo, F., \& Borges, B. (1991). Os arquivos imperfeitos: memória social e cultura eletrônica. São Paulo: Perspectiva.

Donker-Duyvis, F. (1942). Normalisatie op het gebied der documentatie. The Hauge, Netherlands: NIDER.

Edmondson, R. (1998). Uma filosofia dos arquivos audiovisuais. Paris: UNESCO.

Gil, A. C. (2008). Métodos e técnicas de pesquisa social (6a. ed.). São Paulo: Atlas.

Hernández-Alfonso, E. A. (2007). Indización y Resumen. La Habana: Editorial Félix Varela.

Joly, M. (2012). Introdução à análise da imagem (14a. ed.). Campinas: Papirus.

Le Coadic, Y.-F. (1994). A ciência da informação. Brasília: Briquet de Lemos.

Lima, V. M. A. (2016). A documentação audiovisual. In J. F. M. Silva \& F. C. Paletta (Eds.), Tópicos para o ensino de biblioteconomia (p. 86-99). São Paulo: ECA-USP.

McCarthy, C. M., \& Targino, M. d. G. (1984). Materiais audiovisuais na sociedade e nas bibliotecas brasileiras. Revista da Escola de Biblioteconomia da UFMG, 13(2), 302-321. Recuperado de http://hdl.handle.net/20.500.11959/brapci/ 76331

Menezes, I. A. (2019). O profissional atuante na preservação audiovisual. Museologia ES Interdisciplinaridade, 8(5), 85103. Recuperado de https://periodicos.unb.br/index.php/ museologia/article/view/24668/21845

Minayo, M. C. d. S., \& Sanches, O. (1993). Quantitativoqualitativo: oposição ou complementaridade? Cadernos de saúde pública, 9(3), 237-248.

Napolitano, M. (2016). Fontes audiovisuais: a história depois do papel. In C. B. Pinsky (Ed.), Fontes históricas (2a. ed., p. 235-290). São Paulo: Contexto.

Nuno, F. F. (2012). Evolução legal dos arquivos audiovisuais e sonoros em portugal. Ponto de Acesso, 6(1), 156-171.

Otlet, P. (1934). Traité de documentation. Brussels: Editiones Mundaneum.

Primo, L., \& Cabral, S. (2014). Produção audiovisual: imagem, som e movimento. São Paulo: érica.
Rodrigues, A. M. L. (2006). A teoria dos arquivos e a gestão de documentos. Perspectivas em ciência da informação, 11(1), 102-117.

Rose, D. (2015). Análise de imagens em movimento. In M. W. Bauer \& G. Gaskell (Eds.), Pesquisa qualitativa com texto, imagem e som: um manual prático (13a. ed., p. 343-364). Petrópolis: Vozes.

Salaverría, R. (2014). Multimedialidade: informar para 5 sentido. In J. Canavilhas (Ed.), Webjornalismo: 7 características que marcam a diferença (13a. ed., p. 343-364). Covilhã, Portugal: LabCom.

Santana, L. A. (2019). Documentos audiovisuais no brasil: trajetória, institucionalização e novas perspectivas (Dissertação de mestrado não publicada). Faculdade de Filosofia e Ciências, Universidade Estadual Paulista, Marília. (Tese de doutorado)

Saracevic, T. (1996). Ciência da informação: origem, evolução e relações. Perspectivas em Ciência da Informação, 4162. Recuperado de http://portaldeperiodicos.eci.ufmg.br/ index.php/pci/article/view/235/22 (Trad. Ana Maria P. Cardoso)

Tartaglia, A. R., \& Butruce, D. (2015). Entre letras e imagens: o acervo audiovisual no arquivo da academia brasileira de letras. Revista do Arquivo Geral da Cidade do Rio de Janeiro(9), 327-340. Recuperado de http://wpro.rio.rj.gov.br/ revistaagcrj/wp-content/uploads/2016/11/e09_a19.pdf

Tauil, J. C. S., \& Simionato, A. C. (2016). O estado da arte da preservação de acervos audiovisuais. In Anais do XI Seminário de Pesquisa em Ciências Humanas. Editora Edgard Blücher. Recuperado de https://doi.org/10.5151/ sosci-xisepech-gt1_12 doi: 10.5151/sosci-xisepech-gt1_12
Como citar este artigo (APA):

Souza, J. J. (2021). Documentação Audiovisual na Ciência da Informação e Ciências da Comunicação. AtoZ: novas práticas em informação e conhecimento, 10(1), 15 - 24. Recuperado de: http://dx.doi.org/10.5380/ atoz.v10i1.75362 